\title{
Temporal Mesh Conjecture
}

Deep Bhattacharjee ${ }^{1}$, Aruna Harikant ${ }^{2,3}$, and Sanjeevan Singha Roy ${ }^{4}$

${ }^{1}$ Electro-Gravitation Simulation and Propulsion Laboratory, AATWRI Aerospace and Defense

${ }^{2}$ Indian Institute of Technology Mandi

${ }^{3}$ Tehsil Sadar

${ }^{4}$ Department of Physics, Birla Institute of Technology

November 30, 2020

\section{Hosted file}

PDF-Time Mesh Conjecture.pdf available at https://authorea.com/users/379677/articles/495904temporal-mesh-conjecture 